\title{
ARTIGOS
}

\section{ITINERANTE FUTEBOL CLUBE: a desconstrução do torcer e as relações entre clubes e torcidas}

\author{
Alexandre Francisco Alves ${ }^{1}$ \\ Silvio Ricardo da Silva ${ }^{2}$
}

\section{RESUMO}

Em Minas Gerais, nos últimos anos, três clubes transferiram sua equipe para outros municípios, dentre elas o Ipatinga FC que se transferiu para a cidade de Betim, em 2013, retornando para sua cidade natal ao final do mesmo ano. A proposta deste estudo foi compreender o processo de (des)configuração e (re)configuração do torcer nas cidades de Betim e Ipatinga, e como se estabeleceu a relação das torcidas com o Ipatinga FC / Betim EC. Para tal, aplicaram-se formulários e entrevistas semiestruturadas aos torcedores dos dois clubes. Os resultados, embora distintos nas duas cidades estudadas, apontam para um envolvimento dos torcedores com os clubes enquanto uma opção de lazer e que os mesmos são representativos na forma de expressão dos sentimentos que os torcedores apresentam com seus lugares e territórios.

Palavras-chave: Futebol. Clube itinerante. Torcer. Território. Lazer

1 Mestre em Estudos do Lazer. Professor de Educação Física da Rede Municipal. Betim/Minas Gerais, Brasil. E-mail: alves.af@gmail.com

2 Doutor em Educação Física. Professor da Universidade Federal de Minas Gerais (UFMG). Belo Horizonte/Minas Gerais, Brasil. E-mail: prof.srs@gmail.com 
ITINERANT CLUB FOOTBALL: the deconstruction of supporting and relations between clubs and fans

\section{ABSTRACT}

In Minas Gerais, in recent years, three clubs moved his team to other cities, including the Ipatinga FC who moved to the city of Betim, in 2013, returning to his hometown at the end of that year. The purpose of this study was to understand the process of (un) configuration and (re) configuration of the supporting in the cities of Betim and Ipatinga, and how to set the relationship of the fans with the Ipatinga FC / Betim EC. The study invloved the application forms and semi-structured interviews to the fans of both teams. The results, although different in the two cities studied, indicate to involvement of fans with clubs as a leisure option and that they are representative in the form of expression of feelings that fans have with their places and territories.

Keywords: Football. Itinerant Club. Supporting. Territory. Leisure.

\section{ITINERANTE FÚTBOL CLUB: la desconstrución de la afición y las relaciones entre clubes y aficionados}

\section{RESUMEN}

En Minas Gerais, en los últimos años, tres clubes trasladaron su sede a otras ciudades, entre ellas el Ipatinga FC, que se trasladó a Betim, en 2013, volviendo a su ciudad natal a finales de ese año. El propósito de este estudio fue comprender el proceso de (des) configuración y (re) configuración de la afición en las ciudades Betim y Ipatinga, y la relación de los aficionados con los dos equipos. Con este fin, se aplicaron cuestionarios y entrevistas semiestructuradas a los aficionados. Los resultados, aunque diferentes en las dos ciudades estudiadas, indican el envolvimiento de los aficionados con los clubes como una opción de ocio y que son representativos en la expresión de los sentimientos que los aficionados tienen con sus lugares y territorios

Palabras clave: Fútbol. Club Itinerante. Afición. Territorio. Ocio. 


\section{INTRODUÇÃO}

Os chamados clubes itinerantes ${ }^{3}$ estão se proliferando pelo Brasil e suas histórias conhecidas e veiculadas pela mídia, inicialmente com grande surpresa, e posteriormente com certa normalidade ${ }^{4}$, o que pode ser percebido na leitura de diferentes momentos: a partir dos primeiros casos noticiados pelos veículos midiáticos e depois de alguns desdobramentos que resultaram na consolidação ou não dos clubes que realizaram esse processo. Alguns exemplos de migrações e seus desfechos são exibidos na figura 1 .

Essa mudança de sede que, possivelmente, se reflete na identidade dos clubes é mais comum em outros esportes que não fazem parte do circuito clubista. Para Damo (2011), o clubismo é movido pelas rivalidades tradicionais entre os clubes, como as que sustentam os clássicos locais e regionais. No caso, o clubismo ou circuito clubista é a disputa de competições "[...] envolvendo times que representam agremiações normalmente chamadas de clubes, grêmios ou associações" (DAMO, 2011 p. 81). Em modalidades como o voleibol, o futsal e o basquetebol, alguns times são criados levando consigo nomes de empresas e, até mesmo, produtos que são suas marcas registradas, fixam a sede em uma cidade específica e, conforme as expectativas de seus dirigentes em relação às melhorias e interesses de seus patrocinadores podem migrar para outros locais e cidades sem aviso prévio e sem dar satisfação a seus torcedores.

O Ipatinga Futebol Clube (Ipatinga FC), considerado um clube jovem, fundado em 1998, alcançou a projeção nacional após um desempenho expressivo nas competições que disputou se considerarmos seu pouco tempo de existência. Em 2005, apenas sete anos após sua fundação, conquistou o título do Campeonato Mineiro chegando novamente à final no ano seguinte. Em 2006, o clube chegou às quartas de final da Copa do Brasil. No final desse ano, após o vice-campeonato da série C, subiu para a série B do Campeonato Brasileiro.

3 O termo itinerante foi utilizado pela mídia para definir os clubes que mudam de cidade-sede bem como trocam de nome. Pela definição do dicionário Aurélio: 1. Que muda de lugar onde exerce sua atividade; 2. Que é exercido com alteração frequente de local; 3. Que ou quem se desloca, viaja ou passeia. O termo se associa a tudo o que pressupõe a troca constante de lugar, de se deslocar, percorrer itinerários variados.

4 Disponível em: http://globoesporte.globo.com/futebol/noticia/2014/01/fusoes-migracoes-e-trocas-de-nome-oque-os-clubes-fazem-pra-sobreviver.html> Acesso em: 25 mar.2014). 


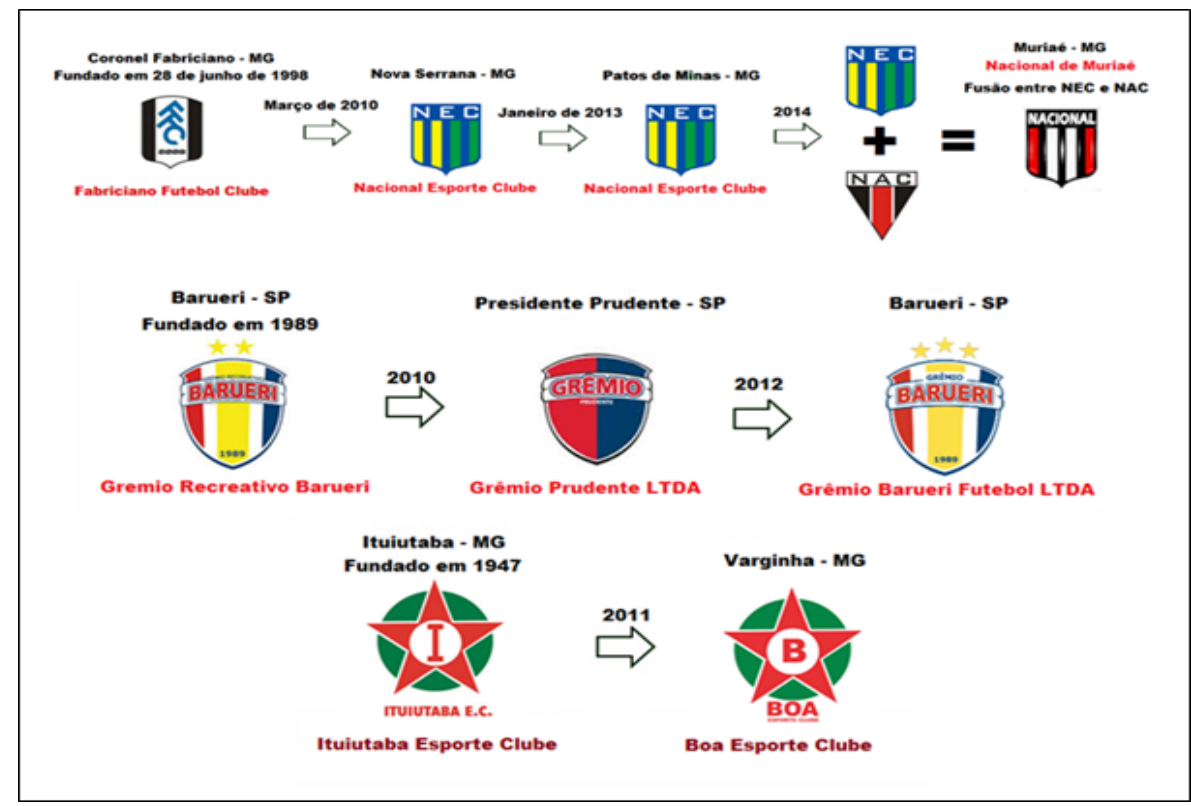

Figura 1 - Desfecho das migrações de alguns clubes

Fonte: Autores

Em 2007, alcançou o vice-campeonato da série B, conseguindo o acesso à série $A$ do Campeonato Brasileiro. Contudo, após uma campanha irregular nesse ano, não conseguiu se sustentar na chamada elite do futebol brasileiro, sendo rebaixado à série $\mathrm{B}$. Em 2010, o clube viveu momentos distintos dentro de campo: chegando à final do Campeonato Mineiro, sendo derrotado pelo Atlético Mineiro. Todavia, na série B do Campeonato Brasileiro, a campanha ruim que realizou o levou ao rebaixamento à série $C$ para disputa no ano seguinte.

Em 2011, o clube realizou uma campanha irregular. No Campeonato Mineiro, foi rebaixado para o Módulo II, enquanto, no Campeonato Brasileiro da Série C, conseguiu acesso à Série B. Já no final de 2012, o clube já ensaiava uma possível saída da cidade.

Em 2013, após a aprovação da Federação Mineira de Futebol (FMF) e da Confederação Brasileira de Futebol (CBF), o clube transfere-se para a cidade de Betim e altera seu nome para Betim Esporte Clube (Betim EC). Foi um ano em que o clube não conseguiu passar da primeira fase do Campeonato Mineiro. Na Série C do Campeonato Brasileiro, foi eliminado pelo Santa Cruz Futebol Clube nas quartas de final.

Ainda, em 2013 o clube anuncia sua volta para Ipatinga. Em 2014, tendo já retornado à cidade natal, o clube participa do Módulo II do Campeonato Mineiro ainda com 
o nome de Betim E.C., em virtude de o registro na FMF e na CBF não ter sido alterado 5 . Em novembro de 2014, obteve a autorização da CBF para realizar a troca para seu antigo novo nome, voltando a se chamar Ipatinga Futebol Clube.

O objetivo geral desse estudo foi analisar o processo de (des)configuração e (re) configuração do torcer nas duas cidades: Betim(MG) e Ipatinga(MG), e como se estabeleceu a relação das torcidas com o Ipatinga FC / Betim EC.

\section{OS CAMINHOS METODOLÓGICOS - AS IDAS E VINDAS COM OS CLUBES}

A abordagem metodológica de caráter exploratório a partir do caso do Ipatinga/ Betim FC constituiu o trabalho de campo, envolvendo aplicação de formulários a 108 torcedores na cidade de Ipatinga-MG. A coleta de dados foi realizada entre os meses de outubro de 2014 a março de 2015 em duas etapas: a primeira, no interstício dos jogos, se ateve à busca dos torcedores nos locais onde costumavam se concentrar nos dias das partidas do clube: o bar, e também, através de indicação de frequentadores, houve o direcionamento para alguns locais onde residiam alguns torcedores indicados no contato. A segunda etapa de coleta foi realizada nos dias de jogos, previamente às partidas do Ipatinga FC pelo Campeonato Mineiro Módulo II de 2015, nas imediações do Estádio Municipal João Lamego Neto.

É importante ressaltar que a aplicação dos formulários ocorreu após o retorno do clube para Ipatinga, em virtude do cumprimento dos prazos para aprovação da pesquisa pelo comitê de ética em pesquisa (COEP - UFMG) e em virtude da rápida permanência do Ipatinga FC na cidade de Betim.

A utilização desses instrumentos de coleta foi baseada em Lakatos e Marconi (2007), levando em consideração um roteiro de perguntas realizadas pelo entrevistador e preenchidas por ele mesmo, a partir das respostas e comentários do pesquisado.

Para a organização e análise dos dados contidos nos formulários, foi utilizado o software SPSS para Windows, versão 21. Foram gerados relatórios, gráficos e tabelas baseados na estatística descritiva.

Em Betim, para onde o clube se transferiu, em 2013, não foi possível a aplicação dos formulários em virtude da dispersão dos torcedores do clube, quando ele estava na cidade. Desse modo, seis torcedores que acompanharam o clube nos jogos participaram da pesquisa entre os meses de novembro de 2014 a março de 2015, sendo feita a opção pela realização de entrevistas semiestruturadas com os torcedores na cidade, o que evidenciou uma profundidade maior nas análises por meio das falas contidas nas entrevistas dos torcedores do Betim EC ao invés do preenchimento de formulários.

5 O clube estava na sexta colocação do campeonato quando foi penalizado com a perda de seis pontos pelo Comitê Disciplinar da FIFA em razão de uma dívida com um Clube de Futebol Português. O Clube permaneceu no Campeonato Brasileiro da Série C, em 2013, após impetrar ação civil pública em tribunal comum, para evitar a perda dos pontos e cair para a zona de rebaixamento, o que não é permitido pelo Código de Justiça Desportiva. Em fevereiro de 2014, o Superior Tribunal de Justiça Desportiva (STJD) ratificou a decisão e rebaixou o time para a Série D. Disponível em: < http://globoesporte.globo.com/mg/grande-minas-vales/noticia/2014/02/ cbf-confirma- rebaixamento-do-ipatinga-para-serie-d-do-brasileiro.html > Acesso em: 02mar. 2014. 
Na organização e análise dos dados qualitativos (as entrevistas semiestruturadas), foi utilizada a análise de conteúdo proposta por Bardin (2011). O estudo foi organizado nas seguintes fases: pré-análise; fase de exploração do material e tratamento e interpretação dos resultados. Na pré-análise foi feita a organização do material com o objetivo de torná-lo operacional. Nessa fase foram transcritas as entrevistas submetendo-as sob o mínimo de tratamento gramatical, sem prejuízo para a mensagem. A leitura flutuante foi essencial para a escolha dos documentos, a formulação de hipóteses e objetivos, além da referenciação dos índices.

Assim, foram elencados os quadros temáticos de análise que abriram possibilidades de condução para elencar as categorias do estudo. Posteriormente, as entrevistas foram submetidas à análise temática e sequencial, observando-se as regras propostas por Bardin (2011) de exaustividade que leva em consideração todos os elementos que compuseram o corpus da análise; de representatividade, que considera a escolha da amostra a ser analisada; de pertinência, que orienta que os documentos estudados devem ser adequados como fonte de informação, devendo ser relacionados ao objetivo da análise. Por fim, a regra da homogeneidade prevê que os documentos retidos devem ser homogêneos, devendo obedecer a critérios precisos de escolha, não apresentando elementos de singularidade além desses critérios.

A segunda fase consistiu na exploração do material com a definição de categorias por meio de um sistema de codificação (categorias primárias, conceito norteador, categoria secundária e categoria final). As informações dos discursos dos sujeitos foram codificadas e categorizadas de forma qualitativa e organizadas de maneira a aprofundar o conteúdo das mensagens com o objetivo de obter pontos de convergência e divergência com os discursos dos sujeitos transcritos na fase de pré-análise. Nesse sentido o mapeamento do discurso dos sujeitos a partir dos temas levantados, conduziu à criação das seguintes categorias de análise: a cidade de Betim e o futebol; os torcedores, sua relação com o clube e o futebol como opção de lazer; o torcer após a saída do clube da cidade.

$\mathrm{Na}$ fase final, tratamento e interpretação dos resultados a perspectiva foi elencar pressupostos teóricos que contribuíssem para ampliar as discussões sobre o torcer como forma de lazer, e a criação de identidades e pertencimento dos torcedores com os clubes de futebol. Nesse sentido, a matriz de interpretação orientou para os elementos subtendidos nas mensagens, os quais puderam ser relacionados com as vivências socioculturais dos sujeitos, e foram percebidas as ideias, intencionalidades, interesses e possibilidades acerca do torcer e do apego por um clube de futebol.

\section{O IPATINGA FC E A RELAÇÃO COM OS TORCEDORES}

$\mathrm{O}(\mathrm{s})$ Clube(s), os torcedores

O Ipatinga FC nasceu, em 1998 na cidade de Ipatinga, localizada na região conhecida como Vale do Aço, por apresentar um grande polo siderúrgico dedicado à produção 
de aço. O clube nasceu da profissionalização de um clube amador da cidade chamado Novo Cruzeiro Futebol Clube, sendo registrado na FMF no dia 21 de maio de 1998 e recebeu o nome e as cores da cidade.

Para selecionar os sujeitos do estudo, os critérios para compor a amostra eram: se declarar torcedor do Ipatinga FC, mesmo não sendo torcedor exclusivo e ter acompanhado o clube antes da saída da cidade. Um total de 54,6\% se declararam torcedores exclusivos do clube e quando esses dados são cruzados com a faixa etária, pode ser verificado um grande número de torcedores jovens, abaixo dos 35 anos que declararam o Ipatinga o único clube do coração (tabela1).

Interessante também é o fato de 40,8\% dos torcedores acima de 40 anos se declararem torcedores e, mesmo sendo um clube jovem, com apenas 16 anos de fundação, o vínculo das pessoas com o clube se deu a partir de uma forte significação e um pertencimento a ponto de serem desfeitos vínculos anteriores e criados novos laços afetivos.

Tabela 1 - Torcedores exclusivos do Ipatinga conforme a faixa etária

\begin{tabular}{lc}
\hline Faixa etária & \% de torcedores do IFC \\
\hline 18 a 19 anos & 10,2 \\
20 a 24 anos & 3,4 \\
25 a 29 anos & 13,6 \\
30 a 34 anos & 10,2 \\
35 a 39 anos & 8,5 \\
40 a 44 anos & 5,1 \\
45 a 49 anos & 5,1 \\
50 a 54 anos & 8,5 \\
55 a 59 anos & 13,6 \\
60 a 64 anos & 22,0 \\
\hline
\end{tabular}

Fonte: Autores

Essa opção exclusiva de torcer pelo Ipatinga FC pode ser explicada pela representatividade do clube, que participava de inúmeras competições durante todo o ano, permitindo aos torcedores a possibilidade de acompanhá-lo com uma maior frequência do que se estivesse apenas participando dos campeonatos regionais, que geralmente acontecem apenas no primeiro trimestre do ano. Esse fato pode ter gerado uma maior proximidade e identificação dos torcedores com o clube na medida em que o clube conquistou alguns títulos, como o Campeonato Mineiro em 2005 além de obter resultados expressivos em outras competições.

As relações de identidade entre torcedores e times de futebol são construtos históricos e implicam o reconhecimento definido por Hall (2009) como perturbador de que a relação com o outro se define a partir daquilo que falta, daquilo que não é, ou seja, a 
construção da identidade é pelo apego temporário a uma estrutura que faz falta. No caso do futebol, os efeitos do pertencimento a um determinado ethos ${ }^{6}$ mantém essa relação de dependência do torcedor com o clube no sentido de que o torcer dá significado aos hábitos dessas pessoas.

Nesse sentido, a identificação7 com os clubes faz parte de um processo cultural dinâmico que é desenvolvido ao longo do tempo. Essas estruturas dinâmicas que constituem a identidade via práticas simbólicas de representação, por meio das quais os significados são produzidos, é que dão sentido à experiência do torcedor e tornam possíveis as vivências do torcer, seja ele individual ou coletivo. Essa é uma forma pela qual os torcedores se apropriam de seu time. A partir daí, se posicionam e constroem o status de relacionamento com os clubes de futebol que representam os ideais de seu grupo social, sua cidade, seus anseios, permeiam seus discursos e seus sentimentos.

Outro dado interessante é com relação à participação das mulheres na pesquisa. Os dados exibidos na tabela 2 apresentam o número total dos participantes, sendo torcedores abordados em casa, no bar e no estádio. Quando analisado somente no estádio nos dias de jogos do clube, o número de mulheres presentes cai para 8,8\%, enquanto os homens são maioria, 91,2\%. Embora a orientação para aplicação dos formulários tenha sido para a escolha aleatória de torcedores, os dados encontrados parecem se aproximar da proporção real durante as partidas.

Tabela 2 - Sexo dos participantes da pesquisa

\begin{tabular}{cc}
\hline Sexo & $\%$ \\
\hline Mulheres & 10,2 \\
Homens & 89,8 \\
\hline
\end{tabular}

Fonte: Autores

Segundo Campos (2010), a presença das mulheres nas arquibancadas dos estádios tem ganhado destaque, de maneira que cada vez mais elas contribuem para a construção do espetáculo futebolístico. Para explicar o baixo número de mulheres torcedoras encontrado, ainda há alguns obstáculos e preconceitos que impedem a legitimação das mulheres enquanto torcedoras capazes de manifestar seu pertencimento clubístico e expressar seu interesse pelo jogo também sob os pontos de vista técnico-tático, econômico, social, político e cultural, de maneira que essa construção histórica da imagem da mulher e do homem na nossa sociedade é manifestada também no futebol.

6 Para Bourdieu (2007), o ethos é o conjunto de princípios interiorizados que guiam a conduta do indivíduo de forma inconsciente e que permite a adesão aos valores partilhados por determinado grupo social.

7 Para Hall (2009), estamos vivendo atualmente uma verdadeira explosão discursiva em torno do conceito de identidade. O autor sugere que, ao invés de falar da identidade como uma coisa acabada, seria preferível falar de identificação e vê-la como um processo em andamento (HALL, 2011). 
Os torcedores antes e após a saída do clube da cidade

As relações estabelecidas entre o torcedor do Ipatinga FC antes da saída desse da cidade e consequente mudança para a cidade de Betim podem ser medidas pela frequência com que o torcedor comparecia ao estádio na própria cidade. A grande frequência no Estádio Ipatingão nos jogos do Clube na cidade revela um dado importante no hábito do torcedor. Cerca de 56,5\% dos torcedores relataram ir sempre aos jogos do clube na cidade, 27,8\% declararam ir frequentemente, $13 \%$ disseram ir raramente e 2,8 \% relataram nunca ter comparecido aos jogos do Ipatinga FC na cidade.

Durante a pesquisa de campo, observamos que nos dias de jogos, horas antes do início das partidas, barracas que vendem bebidas e gêneros alimentícios se instalam em frente à bilheteria do estádio, próximo aos portões de entrada, locais onde se concentram os torcedores. As imediações do estádio em dias de jogos constituem intensa manifestação de sociabilidade entre os torcedores, espaço de convivência que atua de maneira contígua ao espetáculo esportivo.

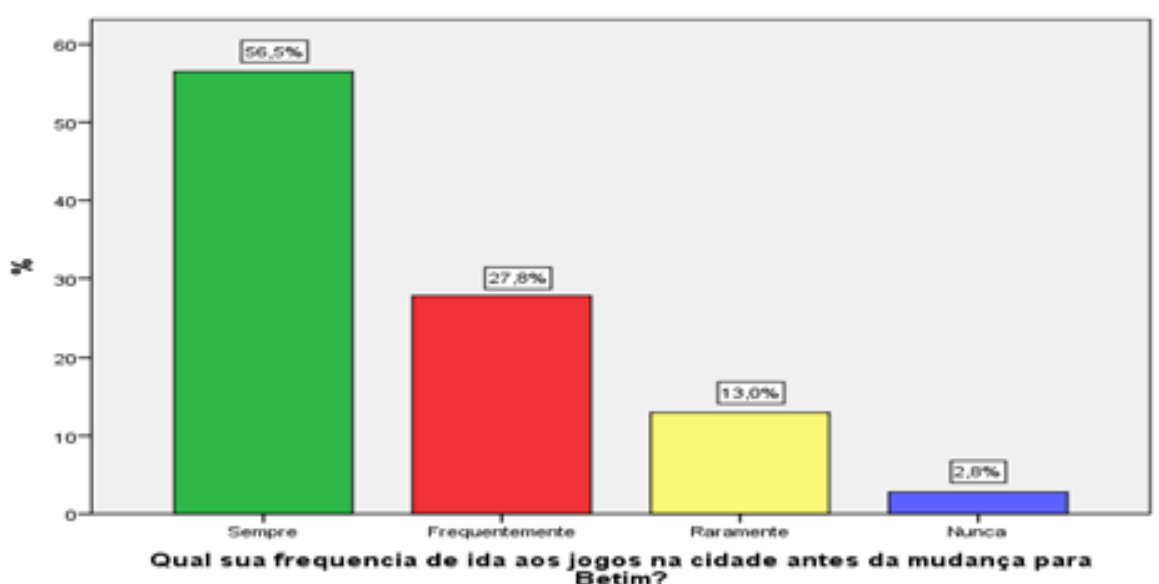

Gráfico 1 - Frequência de ida aos jogos antes da mudança para a cidade de Betim Fonte: Autores

Sobre a assistência dos jogos de futebol no estádio, a experiência de vivenciar o jogo in loco e a apropriação midiática, para Gastaldo (2005, p.114),

[...] a experiência "direta" de assistir a um jogo de futebol no próprio estádio, onde muitos torcedores acompanham a partida com os olhos no gramado e com um radinho de pilha colado ao ouvido, acrescentando à própria experiência a autoridade do discurso do locutor [...] no estádio, o torcedor experimenta o compartilhar de um mesmo evento com milhares de outras pessoas, torna-se massa, dissolve-se na 


\begin{abstract}
"torcida" de seu time; enquanto em sua casa, assistindo à televisão, tal fenômeno social coletivo praticamente não ocorre, salvo em circunstâncias muito especiais, como no momento de um gol importante, por exemplo.
\end{abstract}

Sobre os motivos que levaram os torcedores a acompanhar o Ipatinga FC, os dados apontam para uma grande parte de torcedores ipatinguenses que começaram a torcer pelo clube nos jogos realizadas no próprio Estádio Ipatingão, através de amigos e da divulgação positiva dos resultados do clube. O maior pico de interesse identificado entre os torcedores foi em de 2005, ano em que o Ipatinga FC conquistou o título do Campeonato Mineiro.

Segundo Silva (2001), em sua pesquisa com os torcedores do Clube de Regatas Vasco da Gama, um fator importante mencionado pelos torcedores na escolha do clube do coração, foi a fase de sucesso pela qual o time passa, sendo fatores determinantes a conquista de títulos e o aparecimento de ídolos.

Outro fator de destaque entre os torcedores foi o aparecimento de torcidas organizadas Em Ipatinga, mesmo com o curto período de existência do clube, foram encontrados torcedores de 6 torcidas organizadas, conforme o gráfico 3.

Nome da toreida organizada

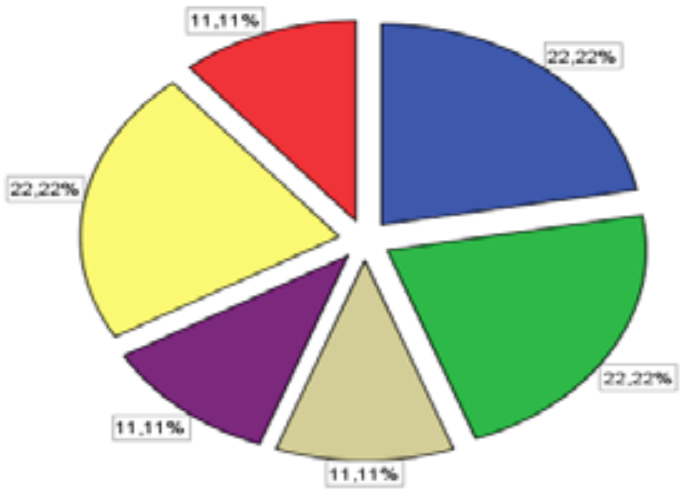

UTigrâo de aço

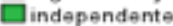

$\square$ Orkutigre

Ipatigrấo

DRaça Jovem

$\square$ Raça Quadricolor

Gráfico 2 - Torcidas organizadas citadas pelos torcedores do Ipatinga FC Fonte: Autores

Em relação à migração do Ipatinga FC para a cidade de Betim, ocorrida no início de 2013, a maioria dos torcedores pesquisados, 43,5\% declararam não querer saber mais do time, $36,1 \%$ disseram continuarem torcendo pelo Ipatinga FC; $17,6 \%$ se mostraram indiferentes e 1,9\% começaram a torcer por outro clube na cidade (gráfico 3). 


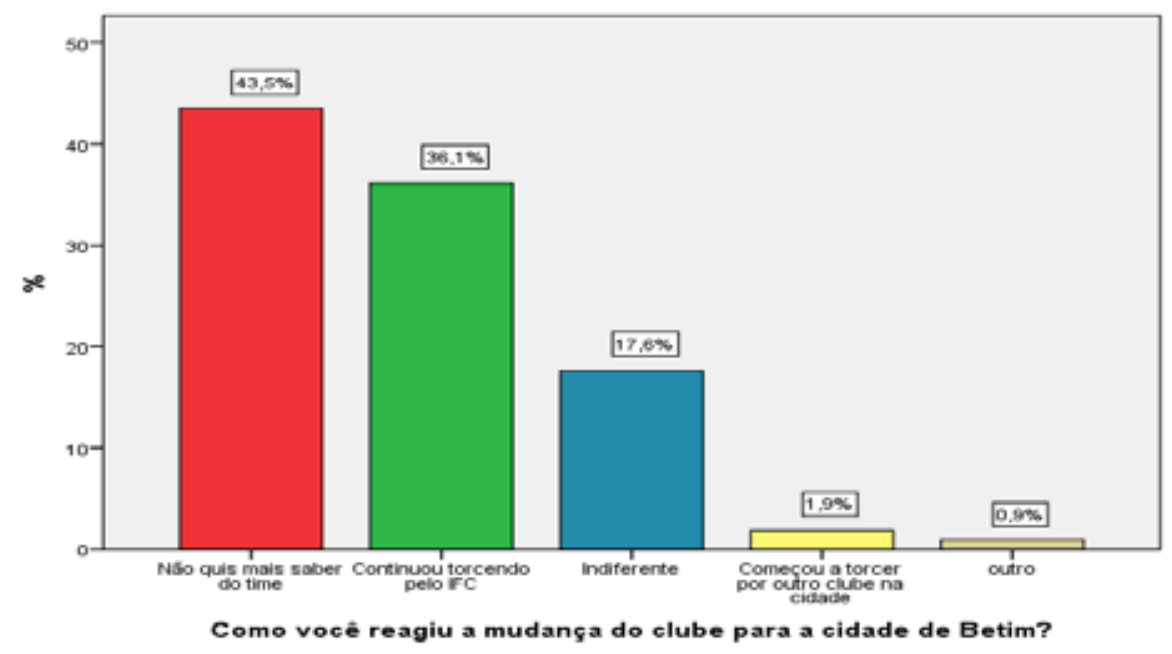

Gráfico 3 - Reação do torcedor após a saída de Ipatinga Fonte: Autores

Esse processo de transferência dos clubes para outras localidades parece levar em consideração apenas o fator econômico e em alguns casos, principalmente no interior, de subsistência desses clubes que passam a depender de instalações, recursos e serviços provenientes de prefeituras e agentes públicos.

Em outra mão, essa mercadorização nos clubes de futebol é a incorporação de medidas comuns ao meio empresarial que traz consigo novos processos, novas mercadorias e novos atores, incluindo uma vasta clientela consumidora da mercadoria. Assim, o futebol torna-se o carro chefe da indústria do entretenimento, sendo explorado de diversas maneiras, constituindo o tema central do apelo publicitário para vender de tudo, e sua plasticidade permite que seja comercializado de diversas formas (ALVITO, 2006).

Desse modo, o futebol brasileiro que ao longo do tempo esteve assentado à logica do pertencimento baseado em valores e tradições que se constituem nos laços afetivos entre torcedor e clube, se utilizou desses meios para trazer os conceitos e práticas empresariais modificando essas relações e transformando meramente o futebol em produto, os torcedores em consumidores e os jogadores em mercadoria.

O cenário esportivo com a saída do clube parece ter aberto novas possibilidades. Em Ipatinga, um novo clube foi fundado, o Novo Esporte Ipatinga, sob o desígnio de um clube-empresa. Apesar da frustração dos torcedores após o fim do Ipatinga FC, 16,7\% dos torcedores disseram ter aprovado a criação do novo clube. 42,6\% dos torcedores que acharam a iniciativa boa, houve observações a respeito da possibilidade do início de um novo time, que poderia gerar identificação nos torcedores. Assim, com investimentos poderia haver melhorias e o Novo Esporte Ipatinga poderia até surgir como um substituto do Ipatinga FC. 


\section{Relação com clube após o retorno para a cidade}

No mesmo ano da partida, chegava o momento do clube reencontrar sua torcida. Com o Ipatinga FC já de volta à cidade os torcedores foram perguntados sobre o seu retorno e os dados apontaram para 76,9\% de aprovação, ou seja, a maioria dos torcedores abordados aprovou avaliando como muito bom. As observações dos torcedores remetem mais uma vez ao futebol como opção escolhida para o lazer enquanto marco da sociabilidade torcedora: voltamos a nos encontrar domingo no campo, foi o relato de um torcedor do clube.

Especificamente no Brasil, uma atividade que se destaca como lazer é o futebol, podendo ser considerado como um dos mais importantes elementos da cultura nacional e de lazer, "[...] ele é parte da cultura brasileira e, assim, entendê-lo como um espaço no qual o povo pode dramatizar, vivenciar e atualizar emoções" (DAOLIO, 2006, p. 116). Ainda, segundo Daolio (2006), o futebol está arraigado no nosso cotidiano, não sendo possível deixar de vê-lo, ouvi-lo ou pelo menos saber sobre ele.

Quando questionados se voltaram a torcer pelo Ipatinga, 93,5\% responderam positivamente. A paixão pelo clube, o relato de que nunca deixaram de torcer pelo Ipatinga FC, a representatividade do clube na cidade e pelo Brasil, além das possibilidades de lazer e convívio com os amigos foram as categorias elencadas baseadas nas justificativas dos torcedores.

\section{ANÁLISE DAS ENTREVISTAS DOS TORCEDORES DO BETIM EC}

\section{A cidade de Betim e o Futebol}

A cidade de Betim, localizada na região metropolitana de Belo Horizonte, se destaca pelo polo industrial que abriga, sendo considerada uma cidade metalúrgica com grande parte do polo industrial destinado ao fornecimento de peças e serviços para o setor automotivo. Além disso, o polo petroquímico se evidencia, sendo o único do estado de Minas Gerais8. Desse modo o destaque na economia de Betim pode ter sido o responsável pela atração do Ipatinga FC à cidade, tendo em vista o grande número de empresas voltadas para o setor automobilístico, de metalurgia e o refino dos derivados de petróleo.

A chegada do clube à cidade de Betim criou expectativa nos torcedores. A cidade é carente de opções de lazer e permanece ao longo dos anos sem investimentos públicos direcionados à sua vivência, como parques públicos, por exemplo.

Os torcedores, sua relação com o clube e o futebol como uma opção de lazer

São apresentados alguns dados sobre os sujeitos para situá-los no contexto da pesquisa (tabela 2). Todos os entrevistados são do sexo masculino. As torcedoras

8 Fonte: IBGE. Disponível em: < http://cidades.ibge.gov.br/xtras/perfil.php?lang = \&codmun $=310670 \&$ search $=$ | | infogr\%E1ficos:-informa\%E7\%F5es-completas> Acesso em: 08 abr.2015. 
identificadas e contatadas não demonstraram interesse em participar da pesquisa. A faixa etária entrevistada compreende dos dezenove aos trinta e cinco anos e sua média de idade aproximada compreende trinta anos.

Tabela 2 - Torcedores entrevistados

\begin{tabular}{cccc}
\hline Torcedor & Idade(anos) & Clube & Ocupação \\
\hline T1 & 35 & Atlético Mineiro & Advogado \\
T2 & 33 & Atlético Mineiro & Téc. de segurança do trabalho \\
T3 & 33 & Flamengo & Cabelereiro \\
T4 & 24 & Cruzeiro & Jornalista \\
T5 & 34 & Atlético Mineiro & Fisioterapeuta \\
T6 & 19 & Cruzeiro & Conferente de processo em logística \\
\hline
\end{tabular}

Fonte: Autores

Interessante analisar como todos os torcedores têm seu clube de coração e mesmo com esse pertencimento clubístico, houve uma aproximação com o Betim EC que definiu a participação dos torcedores, suas experiências e vivências durante a trajetória do clube na cidade.

Antes mesmo da chegada do clube ao município de Betim, alguns torcedores ficaram sabendo, por meio da imprensa, que o Ipatinga FC estava deixando a cidade e seu provável destino seria Betim. Foi criada essa expectativa, e a recepção dos torcedores com a confirmação do fato foi positiva, como relata o torcedor 04 .

"Eu acompanho muito os esportes pela Itatiaia9. Surgiu a possibilidade, era final de 2012 se não me engano. Essa possibilidade do Ipatinga (FC) ir para Betim. Aí pensei: se vier seria bom." (T4)

Em Betim, o clube não realizou jogos na própria cidade em virtude de não haver estádios em condições aprovadas pela FMF para a realização de partidas oficiais. Os jogos do Betim EC, como mandante, foram realizados em cidades distantes, como Nova Serrana e Sete Lagoas (95 e 85 km de distância, respectivamente).

Mesmo com as dificuldades impostas pela distância, os torcedores do Betim EC relataram que foram à maioria dos jogos, comparecendo frequentemente às partidas do clube realizadas "em casa". Nos jogos fora de casa, a frequência era menor, mas os torcedores relataram terem ido a alguns jogos em que o clube era visitante.

9 Rádio Itatiaia é uma emissora que transmite seu sinal para o estado de Minas Gerais. Tem uma programação esportiva voltada principalmente para a cobertura do futebol. 


\begin{abstract}
"Quando era viagem fora a gente acompanhava os jogos, todos os jogos dentro de Minas Gerais a gente acompanhava, fora também a gente conseguia ir. Fomos a Três Corações, a gente tinha uma boa convivência com o clube lá. Todos os jogos a gente fazia caravana, trinta, quarenta, cinquenta pessoas. Mas quando o jogo era muito longe, aí a gente colocava três carros para ir. Carro dividido, moto, mas a maioria dos jogos era de ônibus". (T6)
\end{abstract}

Apesar de apenas 11 meses de convivência na cidade, foi criada uma torcida organizada. Denominada de Loucos do Alambrado, fundada por um grupo de amigos no momento em que ficaram sabendo que o clube se mudaria para Betim.

Se pensarmos que há uma identificação com o clube, o que leva os torcedores a produzirem valor ritual para os componentes da TO, o próprio clube, seu escudo, sua bandeira, seus símbolos, as cores, as camisas dos jogadores que passam a representar, não só o clube, mas também os próprios torcedores que se identificam com eles e os tratam como sagrados (CÉSAR, 1982).

A produção de símbolos e a criação de uniformes pela torcida organizada Loucos do Alambrado era sua marca registrada pela qual se identificavam e se distinguiam perante os demais torcedores (figura 3).

"Não tem nada melhor que uma torcida que motiva o clube, que está ali perto do alambrado. Aquele jeito louco de torcer mesmo. Aí a gente criou a Loucos do Alambrado, fica ali, na parte do estádio perto do gol, perto do alambrado mesmo. A gente confeccionou muitas camisas de modelos diferentes, tinha camisa infantil, a gente tinha patrimônio de bandeiras, três faixas, uma de quarenta, uma de trinta e uma de vinte metros, bateria completa com mais de vinte instrumentos pra dar aquela agitação. Tudo com nosso nome e o símbolo do coringa, que representava a Loucos do Alambrado". (T6)

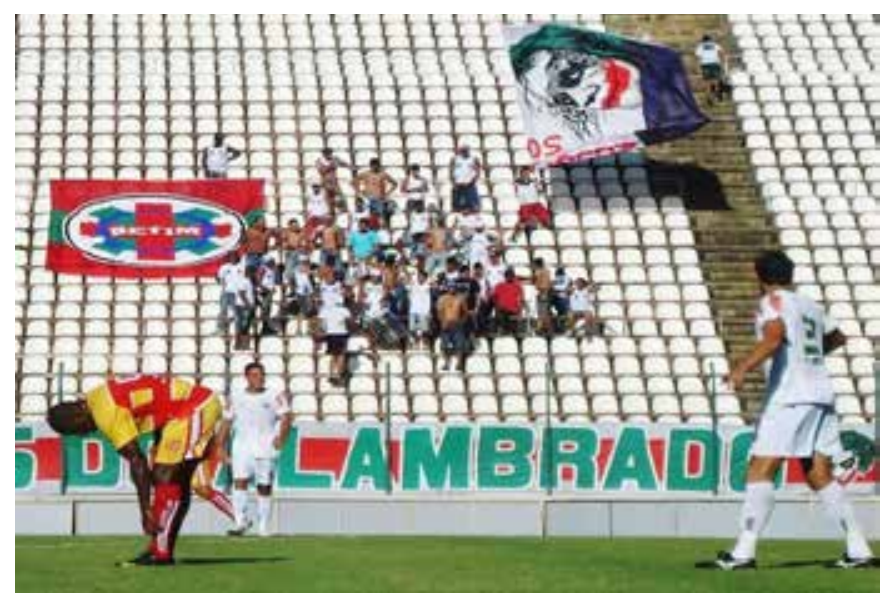

Figura 2 - Os símbolos da torcida e sua organização nos jogos

Fonte: Autores 
Segundo César (1982) que, em seu estudo, pesquisou sobre a torcida organizada Gaviões da Fiel, o símbolo é entendido como algo que tem significado, valor social e ritual, tornando-se, para os torcedores organizados, algo sagrado. É somente por meio dos seus símbolos que eles se identificam entre si em um objetivo comum.

Para os torcedores betinenses os motivos que os levaram a acompanhar o clube se baseiam primordialmente na oportunidade de ter um clube na cidade para torcer, sendo uma forma de representar o município e um meio de distinção dos demais torcedores.

“Era uma maneira de divulgar todos os trabalhos que são realizados no município, você consegue divulgar através das mídias hoje, os meios de comunicação, você consegue divulgar os espaços históricos, as atividades sociais que são desenvolvidas, no município. Então, a ideia era que o Betim diante da força da mídia, poderia então estar divulgando essas modalidades do município nos meios de comunicação." (T1)

Outro fator de afeição entre torcedor e clube, no caso do Betim EC, foi sua instalação em um centro de treinamento na periferia da cidade, e a relação próxima que se estabeleceu desencadeou um laço afetivo que gerou uma proximidade ainda maior com o clube.

\footnotetext{
"A gente tinha seis ou sete jogadores que tínhamos um relacionamento bom, chegaram a ir a nossa casa, a gente ir a casa deles também. Fazíamos churrasquinho e eles passavam lá pra dar uma força, cumprimentar a gente. Tinha uma relação boa com todo mundo ali. Todo mundo de Betim gostava de estar com a torcida e a torcida gostava de estar com o Betim." (T6)
}

"Porque se alojou bem no nosso bairro, o alojamento era no nosso bairro e a gente teve interesse também pelo nome, porque estava levando o nome da cidade, que sempre foi carente de um time de futebol." (T2)

O futebol foi declarado como uma opção de lazer pelos entrevistados. Os relatos foram que a cidade de Betim tem poucas opções de lazer em sua estrutura, poucos parques públicos, poucas praças, ou seja, uma estrutura de lazer insuficiente que o futebol passou a preencher principalmente nos finais de semana, mesmo com os jogos sendo realizados em outras cidades. O torcedor 02 é enfático.

"A cidade de Betim está muito carente, a gente não tem lazer, então a gente se uniu muito, amigos, família, em prol de uma forma de lazer no geral. Em questão de grandeza de um time para Betim, eu acho que é até menos importante, a gente sente falta de um time. Se ele é da Série A, B, C ou D, o importante era ter um time aqui na cidade pra gente poder acompanhá-lo". (T2)

A assistência a espetáculos esportivos é uma das formas mais praticadas de lazer no mundo segundo Reis (1998). Ir ao estádio representa um espaço de sociabilidade entre as pessoas conforme relato dos torcedores 4 e 6 . 


\begin{abstract}
"Ser torcedor, ir ao estádio, sair com os amigos para acompanhar os jogos, já mostra que você faz algo diferente. Hoje em dia tem televisão, que você pode acompanhar o jogo, mas o estádio é diferente, a locomoção, o momento de encontrar com todo mundo, acompanhar o esporte. Isso é que é o diferencial, é o lazer, fora o que a gente já tem. Betim tem cinema, não tem teatro, não tem muito lugar pra sair à noite. O futebol seria uma boa alternativa". (T4)
\end{abstract}

“No final de semana a família ir ao estádio, isso aí é a melhor coisa do mundo. O pai levar o filho pro estádio, namorado e namorada ir pro estádio, isso aí é proporção de lazer para milhares de pessoas. Então, futebol é lazer, futebol é alegria". (T6)

\title{
O torcer após a saída do clube da cidade
}

Sobre a saída do time da cidade, os torcedores se surpreenderam quando o clube anunciou seu retorno à Ipatinga o que gerou grande desapontamento.

“Foi uma decepção muito grande, a gente estava querendo montar uma torcida, pra gente acompanhar o time, talvez até fora da cidade e por causa de uma não conquista, o time ter voltado para a cidade de Ipatinga". (T2)

“Uai, a gente ficou na mão, né? Estava todo mundo empolgado, gritando: Betim, Betim, aí o time voltou pra lá e nos deixou órfãos. A única coisa que nós poderíamos fazer é ficar triste. Todo mundo estava feliz com o time e de uma hora para outra vem uma notícia dessa". (T3)

Alguns torcedores continuaram acompanhando as notícias do clube quando ele retornou para Ipatinga.

"Ele criou uma ligação muito forte com o time apesar dos problemas financeiros, mas se tornou um time que eu acompanho. Eu sei que ele hoje está no Módulo II, mas está brigando pelo acesso. Eu não deixei de acompanhar. Fiquei com ele até na briga para a Série $\mathrm{C}$ e depois da punição, sendo rebaixado para a Série D. Então, essa ligação não acabou, ela continua e eu tenho essa simpatia pelo time. Torço pelo torcedor de Ipatinga, apesar de não morar lá, mas no período em que ele esteve em Betim, criou uma ligação muito forte não só comigo, mas com muitos torcedores daqui". (T4)

Sobre a criação de outra equipe na cidade, o Futebol Clube Betinense, a desconfiança é uma atitude recorrente. Os torcedores não declararam muito entusiasmo ao relatarem sua opinião sobre a criação do novo clube.

“O (FC) Betinense veio pra tentar ocupar o lugar do Betim (EC), estava tentando conquistar, mas não conseguiu. Muita gente ficou chateada com a volta do time. Eu acho que não deu certo isso, foi mais uma jogada. O Betim (EC) foi embora, aí aparece uma nova equipe pra todos abraçarem a ideia. Mas os betinenses ficaram 
chateados. Foi legal eles tentarem criar uma nova equipe, mas parece que eles tentaram ficar na aba do Betim (EC) e eu acho que isso não foi legal". (T6)

Talvez essa iniciativa de se criar um clube, com a recente saída do Betim EC, tenha se dado em função da necessidade de estabelecer uma identidade com um time com raízes no próprio município.

Em linhas gerais, os torcedores depositaram suas fichas em um clube que já carregava uma história vivida em outra cidade. O clube já chegava com a carga de títulos e conquistas e, talvez, essa realidade tenha depositado nos torcedores uma confiança na recuperação da equipe que já não vinha tendo resultados positivos nos últimos anos.

De maneira simultânea, as cidades de Betim e Ipatinga viviam momentos distintos. Os torcedores do Betim EC avaliam a iniciativa do clube como mal planejada. Nem sempre os jogos em casa aconteciam aos finais de semana. Pelo calendário de determinadas competições havia jogos no meio da semana, o que dificultava a ida dos torcedores ao estádio.

"se tivesse um estádio seria muito mais fácil. Se fosse tudo planejadinho e o Betim (EC) tivesse vindo pra cá com estádio pronto, o time estava aí, deslanchando nas alturas." (T6)

A possibilidade de ter um estádio de futebol, na visão dos torcedores, pode representar uma significativa opção de lazer. As necessidades de lazer de uma população são aquelas que os sujeitos elegem como importantes para eles próprios e para seu grupo.

\section{CONSIDERAÇÕES FINAIS}

Com base nas informações coletadas nas duas cidades, podemos concluir que os clubes de futebol são representativos na forma de expressão dos sentimentos que os torcedores apresentam com seus lugares e territórios. No futebol brasileiro, a existência de um clube está ligada a um conjunto de fatores que trazem significado a determinado grupo social. O ser, o pertencer revelam uma compreensão da espacialidade que, a partir de fatores de ligação territorial, podem definir as conexões identitárias que as pessoas definem como um clube, um lugar.

Por meio dos dados obtidos nos formulários com os torcedores do Ipatinga FC, verificamos laços identitários entre torcedor e clube que representam a comunidade via ligação territorial e afetiva, num sentimento de pertencimento descrito por seus membros por meio da enunciação e pelo comportamento verificado nos dias de jogos na cidade. Durante o período em que o clube esteve ausente da cidade, parece ter havido certa resignação dos torcedores. Contudo, surgiu uma esperança contida de que o clube voltaria a ser o mesmo vitorioso, ocupando novamente seu espaço representativo.

Em meio a esse imaginário futebolístico, a desconfiança também ocupou os espaços de debate do ipatinguense assim que a possibilidade do retorno do clube à cidade se 
concretizou. Apesar disso, os dados obtidos durante o preenchimento dos formulários e observações, confirmam a representatividade do clube para a população da cidade, sobretudo um espaço de socialização e convivência que tem em um município do interior suas peculiaridades. Em Ipatinga, o clube era e continua sendo uma marca importante de pertencimento territorial que tem no clube um instrumento que reforça esses laços de pertencer.

Em Betim, o bairro em que o clube se instalou parece ter possibilitado uma conexão mútua que permitiu um grande envolvimento dos torcedores e a formação de uma identidade com o time que envolvia grande parte da comunidade, principalmente nos finais de semana, contribuindo para reforçar os laços afetivos com o local onde moram.

Por meio das entrevistas analisadas na cidade de Betim, com os torcedores que acompanharam o clube no breve período de janeiro a novembro em que esteve na cidade, percebemos o quanto o futebol é relevante para os membros da sua comunidade. Os relatos dos entrevistados remetem não somente ao futebol espetacularizado, mas às formas mais diversas de vivenciar o futebol enquanto lazer. Parece ter havido em Betim uma apropriação do clube num sentido territorial. O clube se estabeleceu em um bairro da periferia do município e, por meio de uma boa relação com a comunidade, fundou um envolvimento que conectou torcedor e clube.

Esse envolvimento faz referência à construção de laços de identidade a partir da relação com o lugar, ou seja, do afeto pelo espaço físico. Essa relação é marcante no sentido de que toda a organização e mobilização da torcida se deram a partir do bairro onde o clube se instalou. Isso fica evidente observando-se as viagens para torcer nas cidades quando o clube era mandante que tinham como ponto de partida o bairro.

Apesar do papel de protagonista que o futebol tem desempenhado nas discussões acerca da organização administrativa do esporte no Brasil, mais estudos devem ser dedicados ao entendimento dessas relações em contextos diferentes.

As discussões suscitadas pelo futebol recentemente têm se mostrado importantes, e a academia deve reafirmar seu papel de protagonista na discussão dos temas relevantes para a sociedade. Não só o futebol, mas os esportes de maneira geral constituem um canal aberto para discussões de gênero, identidades étnicas e políticas públicas dentre outros.

\section{REFERÊNCIAS}

ALVITO, Marcos. A parte que te cabe neste latifúndio: o futebol brasileiro e a globalização. Análise Social, v. 41, n. 179, p.451-74 2006. Disponível em: < http://www.scielo. oces. mctes.pt/pdf/aso/n179/n179a07.pdf > Acesso em: 26 nov. 2014.

BARDIN, Laurence. Análise de conteúdo. São Paulo: Edições 70, 2011.

BOURDIEU, Pierre. A distinção crítica social do julgamento. Zouk. Porto Alegre, 2007. CAMPOS, Priscila Augusta Ferreira. Mulheres torcedoras do Cruzeiro Esporte Clube presentes no Mineirão. 2010, 144 p. Dissertação (Mestrado em Lazer) - Escola de Educação Física, Fisioterapia e Terapia Ocupacional, Universidade Federal de Minas Gerais, Belo Horizonte. 
CÉSAR, Benedito Tadeu. Os gaviões da fiel e a águia do capitalismo. 1982, 218 f. Dissertação (Mestrado em Antropologia Social), IFCH/UNICAMP / Antropologia Social. Campinas, 1982.

DAMO, Arlei Sander. Produção e consumo de megaeventos esportivos - apontamentos em perspectiva antropológica. Escola Superior de Propaganda e Marketing. Revista Comunicação, Mídia e Consumo, São Paulo, v. 8, n. 21, p.67-92, 2011.

DAOLIO, Jocimar. Cultura: educação física e futebol. 3. ed. rev. São Paulo: Unicamp, 2006.

GASTALDO, Edison. Uma arquibancada eletrônica: reflexões sobre futebol, mídia e sociabilidade no Brasil. Revista de antropologia social, Campos, v. 6. p. 113-123, 2005. HALL, Stuart; WOODWARD, Kathryn; SILVA, Tomaz Tadeu (Org.) Identidade e diferença. A perspectiva dos estudos culturais.. Petrópolis: Vozes, 2009.

LAKATOS, Eva Maria; MARCONI, Marina de Andrade, Metodologia do trabalho científico. São Paulo: Atlas, 2007.

REIS, Heloisa H. B. Futebol e sociedade: as manifestações da torcida. 1998, 164p. Tese (Doutorado em Educação Física) - Faculdade de Educação Física, Universidade Estadual de Campinas, Campinas.

SILVA. Silvio. R. Tua imensa torcida é bem feliz: da relação do torcedor com o clube.2001. 142 f. Tese (Doutorado em Educação Física) Faculdade de Educação Física Universidade Estadual de Campinas, Campinas, 2001.

Recebido em: agosto/2016

Aprovado em: maio/2017 